Letras, Lima. 1977-79. (Nos. 86-87). 129-144.

\title{
Pensamiento Incaico: WIRACOCHA
}

MARIA LUISA RIVARA DE TUESTA

\section{WIRACOCHA O EL PODER Y MANDO DE TODAS LAS COSAS}

La crónica española nos proporciona abundante información acerca de Wiracocha, pero hasta el momento no se ha podido explicarlo convenientemente dentro de la estructura del pensamiento incaico. Así tenemos que el cronista atribuye al Perú primitivo el conocimiento de un ser supremo que identifica con ligereza con el Dios de los cristianos. Esta identificación porta en sí el primer problema para el estudio de Wiracocha; debemos por lo tanto despojarlo cuidadosamente, en la versión del cronista cristiano, del ropaje interpretativo, ya que nuestro propósito está encaminado a desentrañar su sentido y significación en forma objetiva.

Wiracocha es así comúmnente considerado como la entidad de máxima jerarquía enl el mundo religioso epre-hispánico, debido justamente a que el cronista, hombre perteneciente al mundo y la cultura occidental del siglo XVí, al convertirlo al signo cristiano le está otorgando su mayor sentido interpretativo. El hecho de que Wiracocha haya sido identificado con el Dios de los cristianos, explica a su vez la continuidad de su ubicación cumo máxima entidad religiosa (1).

Wiracocha, entidad siempre presente, sea en la mitología, en el poema o en su versión cristianizada, of rece una característica peculiar: se da temporalmente, es decir desenvolviéndose en el tiempo, nunca como algo acabado, fijo o conocido, sino más bien adquiriendo mayor riqueza y contenido de significación a través de su propio quehacer en el tiempo.

Esta primera característica explica que a la llegada de los espa-

(1) "Pachacutec reconoció en sitial superior al sol a otra entidad divina que parece ser un dios antiguo que vuelve a ocupar el sitio más alto, el Dios Wiracocha". p. 139.

cf. Valcárcel, Luis E. Etnohistoria del Perú Antiguo, 7- Religión, 
ñoles y en su indagación se recolectaron datos de diverso nivel racional: desde las formas mitológicas hasta las metafísicas, y explica a su vez algo peculiar y propio de la estructura de pensamiento en el antiguo Perú: el conocimiento adquirido se trasmitía conservando al mismo tiempo la trayectoria de su propio proceso evolutivo-explicativo.

Desde esta perspectiva temporal nos es posible presentar a Wiracocha, con el testimonio que la crónica nos proporciona, en tres estratos diferentes y donde a través de su presencia es posible detectar tres niveles de respuesta racional a la problemática de todo lo existente. Así examinaremos primero la forma mitológica, luego la poemática; nos ocuparemos igualmente de las diferentes modalidades de su significación en la traducción al código occidental, para llegar en última instancia a nuestra interpretación acerca de cuál fue su sentido y significación.

\section{WIRACOCHA EN EL MITO}

Motivo de nuestro primer análisis es la presencia de Wiracocha en el mito, lo que prueba que Wiracocha está enraizado en el proceso de desenvolvimiento explicativo de todo lo existente y aun cuando irá adquiriendo mayor riqueza y contenido de significación, ya se le atribuyen poderes que no solamente sirven para responder a las grandes problemáticas de tipo gnoscitivo, sino que lo van delineando como entidad sui generis.

Las fuentes consultadas, que enuncian la presencia de Wiracocha como personaje mitológico, ofrecen matices $y$ rasgos característicos peculiares de una formar de pensamiento que, aun cuando se ve conectada con las formas de pensamiento universal, nos permite afirmar que Wiracocha es una respuesta peculiar, surgida de una reflexión acorde con la cultura que iría gestándose en este espacio geográfico de nuestro continente. Esta respuesta no pudo haber sido inventada - adulterada por el cronista, quien trató de conservarla en traducción al idioma español, justamente por lo extraño de su contenido y por la admiración que experimentaba ante las formas explicativas que la cultura que trataba de penetrar y conocer había elaborado como verdades inconmovibles.

Ilustra adecuadamente esta situación del cronista el hecho de atribuir al demonio el haberles introducido ilusiones, mentiras y fraudes "haciéndoles entender que él los había criado al principio..." (2) para luego agregar: "Y como por ventura antes tenían alguna noticia (...) de la verdad de lo pasado, y mezclándola con los cuentos

(2) Sarmiento de Gamboa, Pedro. Historia Indica. (6), p. 206. 
del demonio y con otras cosas que ellos mudarían, compondrían y añadirían, como suele hacerse en todas naciones, hicieron una ensalada graciosa, aunque notable en algunas cosas para los curiosos que saben considerar y discurrir por las cosas humanas" (3).

Para el cristiano el que dieran respuestas a las más trascendentales problemáticas de la humanidad no puede ser atribuido sino a la inspiración del demonio; más aún se permite hacer una paralelo entre las verdades de las fábulas y las verdades de la fe cristiana, cuando acota: "Una cosa se debe notar (...) que las cosas que aquí van notadas por fábulas $(. .$.$) ellos las tienen como tan verdades como no-$ sotros las de fé" (4).

El mismo fenómeno se presenta cuando José de Acosta enuncia que "aunque las tinieblas de la infidelidad tienen oscurecido el entendimiento de aquellas naciones, en muchas cosas no deja la luz de la verdad y razón algún tanto de obrar en ellos; y así comúnmente sienten y confiesan un supremo señor y hacedor de todo" (5).

En Bernabé Cobo se dan consideraciones de mayor alcance y de un análisis más profundo, cuando establece que la "forma de idolatría y falsa religión de los Incas era la más concertada y menos apartada de razón" (6) que las de las otras naciones de indios. Por otro lado considera que quien conozca las verdades y desatinos que tuvieron las más nobles y sabias naciones de Europa, como fueron los egipcios, caldeos, griegos y romanos "echará de ver que muchos de aquellos antiguos filósofos tuvieron algunas opiniones más fáciles y de menos fundamento que éstos" ya que "no es poco que ellos mismos se diesen a buscar la causa de cada cosa (...). Antes alcanzaron estos indios algunas cosas guiados por razón natüral, en que pasaron adelante a muchos de los otros gentiles, como es el haber alcanzado a conocer que el verdadero "Dios y primera causa era uno solo, al cual, aunque confusamente, adoraban como a Criador de todo.

Y no parando aquí, se dieron a buscar las razones que había para cada cosa y las causas de donde procedían, con que vinieron en conocimiento de muchas de las segundas causas que se podían ver por los efectos (...) como al sol, al agua, a la tierra..." (7).

Cuestión demoniaca ( $7 a)$, asomo de luz de verdad y de razón, o indagación acerca de la primera o segundas causas, lo esencial en el

(3) Loe. cit.

(4) Loc. cit.

(5) Acosta, José de. Historia Natural y Moral de las Indias. Libro

V, Cap. III, p. 141.

(6) Cobo, Bernabé. Historia del Nuevo Mundo. Libro XIII, Cap.

I, p. 146.

(7) Cobo, Bernabé. Obra cit. Libro XIII, Cap. I, p. 147.

(7a) "mas lo que vemos y entendemos es que el Demonio tuvo poder grandísimo sobre estas gentes, permitiéndolo Dios"

cf. Cieza de León, Pedro. El Señorio de los Incas. Cap. V, p. 11. 
dato que nos proporciona el cronista es la presencia de un proceso racional que busca afanosamente dar una explicación ordenada y coherente acerca de todo lo existente. Así los datos aparentemente arbitrarios que nos proporcionan los cronistas lo que revelan en última instancia son las estructuras profundas, inconscientes del espíritu humano que en el caso de la cultura incaica lo conducen a la postulación de una entidad, con caracteres propios, que es la que tiene en sí y por sí el poder y el mando de todas las cosas.

\section{1) WIRACOCHA Y LA CREACION}

Para los efectos de un adecuado análisis de la presencia de Wiracocha en el mito de creación hemos seleccionado, entre otras, cuatro versiones recogidas por cronistas españoles. Las versiones recogidas coresponden a: Juan de Betanzos (8); Pedro Cieza de León (9); Cristóbal de Molina el cuzqueño (10) y Pedro Sarmiento de Gamboa (11).

Las cuatro versiones recogidas coinciden en el aspecto fundamental tratado en esta parte de nuestro trabajo, es decir que los naturales cuentan y explican cómo se produjo la creación, atribuyéndosela a Wiracocha. Lo interesante y original en la versión mítica es lo que trataremos de analizar a continuación.

El agua como elemento primordial y su tránsito al elemento solar (fuego).

La aparición de Wiracocha, asî como sus actos más importantes de creación, han de Jocalizarse con precisión en la gran laguna del Collao.

Juan de Betanzos al referirse a la aparición manifiesta "dicen que salió de una laguna que es en esta tierra del Perú en la provincia que dicen de Collasuyo, un Señor que llamaron Con Tici Viracocha $(\ldots)$. El cual (...) dicen haber salido otra vez antes de aquella..." (12).

(8) Betanzos, Juan. Suma y Narración de los Incas Cap. 1, "Que trata de Con tici Viracocha, que ellos tienen que fue el Hacedor, e de como hizo el cielo e tierra e las gentes indios destas provincias del Perú" p. 9.

(9) Cieza de León, Pedro. Obra cit. Cap. V. "De lo que dicen estos naturales de Ticiviracocha, $\mathrm{y}$ de la opinión que algunos tienen que atravesó un Apóstol por esta tierra, y del templo que hay en Cáchan y de lo que alli pasó" p. 8.

(10) Molina, Cristóbal de. Ritos y Fábulas de los Incas. I, "Los origenes y el diluvio p. 9.

(11) Sarmiento de Gamboa, Pedro. Obra cit. (6), "Fábulas del origen de estos bárbaros indios del Perú según sus opiniones ciegas". p. 206.

(12) Betanzos, Juan. Obra cit. Cap. I, p. 9. 
Cieza, al referirse a la aparición del sol, igualmente alude a la gran laguna del Collao en los siguientes términos: "salió de la isla de Titicaca, questá dentro de la gran laguna del Collao, el sol muy resplandeciente..." (13).

Hemos querido referirnos al elemento agua como elemento primordial porque se alude a ella en las dos apariciones de Wiracocha, pero si bien es cierto el lago sagrado es la única referencia en que podemos apoyarnos, la secuencia lógica del mito, que se mueve en dos planos, oscuridad-claridad, indica que a la etapa oscuridad corresponde la importancia del agua, pero que luego ésta es reemplazada o eclipsada por la etapa de claridad, debido justamente a la segunda obra de creación, es decir astral, en la que el sol podría ser el símbolo del elemento fuego.

Al haber señalado en el mito dos planos: el de la oscuridad y el de la claridad, debemos adelantarnos a delinear una característica que le es peculiar, aunque poderoso como criador, actúa perfeccionando y rectificando su obra en el tiempo.

El mito, que fundamentalmente está encaminado a resaltar la etapa de claridad, a través de la cual ha de mejorarse la obra, no olvida referirse, justamente, para resaltar la segunda creación, a la primera creación, que aunque importante es insuficiente y defectuosa.

\section{Primera creación por Wiracocha (En la oscuridad)}

Aun cuando las versiones mticas recogidas por los cronistas que hemos señalado están referidas concrétamente a una segunda y póstrera aparición de Wiracocha, que destaca en punto a creación la importancia de su presencia, no omiten signar qué es lo que hizo en su primera aparición.

A la obra de creación efectuada en su primera aparición es a lo que vamos a referirnos, según lo expresan los cronistas. Betanzos reseña: "En los tiempos antiguos, dicen ser la tietra e provincia del Perú escura, y que en ella no había lumbre ni día. Que había en este tiempo cierta gente en ella, la cual gente tenía cierto Señor que la mandaba y a quien ella era subjeta" (14). En este estado de cosas es que aparece Wiracocha, quien ya había aparecido en oportunidad anterior cuando "hizo el cielo y la tierra y que todo lo dejó escuro y que entonces hizo aquella gentc que había en el tiempo de la escuridad ya dicha; y que esta gente le hizo cierto deservicio a este Viracocha, y como della estuviese enojado, tornó esta vez postrera y salió como antes había hecho (15), y a aquella gente primera y a su Señor, en

(13) Cieza de León, Pedro. Obra cit. Cap. V, p. 8.

(14) Betanzos, Juan. Obra cit. Cap. I, p. 9.

(15) de la laguna situada en el Collasuyo. 
castigo del enojo que le hicieron, hizoles que se tornasen piedra luego" (16).

La versión de Cieza es escueta, pero reafirma la etapa de oscuridad, cuando consigna que "Antes que los Incas reinasen en estos reinos ni ellos fuesen conocidos, cuentan estos indios otra cosa muy mayor que todas las que ellos dicen, porque afirman questuvieron mucho tiempo sin ver sol..." (17).

En la versión de Cristóbal de Molina no se hace referencia a la etapa de oscuridad, se menciona "que al tiempo que el Hacedor estaba en Tiahuanaco, porque dicen que aquel era su principal asiento (...), dicen que era de noche..." (18). Igualmente indica que hay en Tiahuanaco muchos bultos de piedra de hombres y mujeres que por no haber obedecido al mandato del hacedor dicen los indios que fueron convertidos en piedra (19).

Sarmiento de Gamboa expresa: "Dicen los naturales de esta tierra, que en el principio, o antes que el mundo fuese criado, hubo uno que llamaban Viracocha. El cual crió el mundo oscuro y sin sol ni luna ni estrellas; y por esta creación le llamaron Viracocha Pachayachachi" (20), agrega en su relato que creó un género de hombres que vivían en oscuridad y a quienes les dejó cierto precepto, que transgredieron, lo que produjo su eliminación por diferentes medios (21); algunos de ellos fueron convertidos en piedra.

Lo que podemos extraer en forma concreta acerca de la primera creación efectuada por Wiracocha es que crea el cielo y la tierra y cierto género de hombres a quienes deja determinadas normas. El hecho de no haber cumplido esas normas parece ser motivo fundamental de su retorno, imponiéndoles el castigo más drástico: los elimina convirtiéndolos eñopiedra (22) lo cual implica una rectificación dentro de lo creado, para proceder a mejorar su obra como veremos en lo que llamaremos la segunda creación de Wiracocha.

\section{Segunda creación de Wiracocha (La claridad)}

En sentido estricto los mitos y fábulas que hemos recogido a través de los cronistas se refieren a la segunda aparición de Wiracocha. Esta segunda venida tiene como objetivo el anular parte de

(16) Betanzos, Juan. Obra cit. Cap. I, p. 9.

(17) Cieza de León, Pedro. Obra cit. Cap. V, p. 8.

(18) Molina, Cristóbal de. Obra cit.. I, p. 13.

(19) Loc. cit.

(20) Sarmiento de Gamboa, Pedro. Obra cit. (6), “...y por esta creación le llamaron Viracocha Pachayachachi, que quiere decir Creador de todas las cosas" p. 207.

(21) Loc. cit.

(22) Es conveniente anotar que se consignan otras modalidades de exterminio como el fuego, el tragárselos la tierra, el mar o el diluvio, pero la conversión en piedra parece ser la más significativa. 
la creación -a los hombres- y rectificar o mejorar lo efectuado, así pues el acento y realce que se da a esta segunda creación de Wiracocha se logra a través de la estructura lógica de la versión que es presentada en un fuerte contraste de un período de oscuridad, frente al de otro, donde la aparición de la luz es el elemento más significativo.

Pasaremos ahora a ocuparnos de la obra que realiza Wiracocha en su segunda aparición, según las fuentes consultadas. Para Betanzos en los tiempos en que toda la tierra era noche, aparecido Wiracocha de la laguna del Collasuyo, se dirigió a un pueblo llamado Tiahuanaco "y como allí (...) en improviso dicen que hizo el sol y el día, y que al sol mandó que anduviese por el curso que anda; y luego dicen que hizo las estrellas y la luna", luego ha de hacer en piedra modelos de cierta gente que después habría de producir (23).

En la versión de Cieza se afirma que en los tiempos en que estuvieron sin ver el sol "y questando desta suerte salió de la isla de Titicaca, questá dentro de la gran laguna del Collao, el sol muy resplandeciente". Por el poder que los indios le reconocían, agrega Cieza, "llamábanle Hacedor de todas las cosas criadas, Principio dellas, $\mathrm{Pa}$ dre del sol, porque, sin esto, dicen que hacía otras cosas mayores, porque dio ser a los hombres y animales $(. .$.$) . Y$ : este tal, cuentan los indios que a mi me lo dixeron, que oyeron a sus pasados, que ellos también oyeron en los cantares que ellos de lo muy antiguo tenían..."(24).

Cristóbal de Molina se refiere a que estando el "Hacedor" (25) en Tiahuanaco, que eтa su principal asiento $(. .$.$) "dicen que era de no-$ che y que allí hizo el Sol y la Luna y estrellas, y que mandó al Sol y I una y estrellas fuesen a la isla de Titicaca, que está allí cerca, y que desde allí subiesen alocielo" u(26).

En la versión de Sarmiento de Gamboa el creador de todas las cosas viendo que los hombres que vivían en la etapa de oscuridad habían generado vicios de soberbia y codicia, transpasando sus preceptos, cayó en indignación, los confundió y maldijo, convirtiéndolos a algunos en piedra a otros en otras formas, pero sobre todo les envió el uno pachacuti (27) que quiere decir 'agua que trastornó la tierra' dejando señales de los que se convirtieron en piedra, para memoria del hecho y para ejemplo de los venideros en los edificios de Pucara, a setenta leguas del Cuzco (28).

(23) Betanzos, Juan. Obra cit. Cap. I, p. 9.

(24) Cieza de León, Pedro. Obra cit. Cap. V, pp. 8-9.

(25) Molina, Cristóbal de. Obra cit. I, "...el Hacedor, a quien en lengua de éstos le llaman Pacha yachachi, $\dddot{y}$ por otro nombre Ticsi Viracocha, que quiere decir incomprensible dios..." p. 16.

(26) Molina, Cristóbal de. Obra. cit. I, p. 13.

(27) Diluvio.

(28) Sarmiento de Gamboa, Pedro. Obra cit. (7), "Fábula de la segunda edad y creación de estos bárbaros, según ellos lós tienen" p. 208. 
Los cuatro cronistas a que nos hemos remitido certifican una segunda creación de Wiracocha en términos de luminosidad a través de la creación de los astros.

Sin embargo, los efectos de su poder no se limitan a este ordenamiento cosmológico, es decir más allá del mundo, sino que se proyectan en el mundo y en los hombres, cuestiones que analizaremos en posteriores trabajos.

Vista la creación en sus aspectos fundamentales, conservada en la visión mítica, examinaremos ahora el poema a Ticci Wiracocha, transcrito en lengua quechua por el cronista indio Joan Santa Cruz Pachacuti (29).

2) WIRACOCHA EN LA POESIA (Poder de todo lo existente, modelador del universo y ordenador).

De este célebre poema, considerado como poesía religiosa inca, es posible extraer conceptos, que no solamente concuerdan con lo expresado en la tradición mítica, sino delinean con más precisión su sentido intrínseco. Se le considera como el poder de todo lo existente: hacedor de la luz, y creador del hombre.

Se le atribuye un poder ordenador que permite que el sol, la luna, el día, la noche, el verano, el invierno no estén libres, sino que a través de su ordenamiento lleguen a lo que se considera está ya señalado y medido por él.

Los fragmentos del poema que alude a Wiracocha en los términos expresados arriba son:

¡Ah Wiraqocha "(30), de todo 9 lo existente el poder!
(...)
Señor,
del universo
el modelador
(...)
Del mundo de arriba,
del mundo de abajo,
del océano extendido,
el hacedor.
(...)
de toda luz naciente
el hacedor

(29) Santa Cruz Pachacuti Yamqui, Joan. Relaciones de Antigüedades deste Reyno del Perú. El poema en quechua está en: I, pp. 287288, II, 289, III, 292, IV, 294. La versión castellana es de J. M. Arguedas. (30) El traductor mantiene el vocablo Wiraqocha sin traducir. 


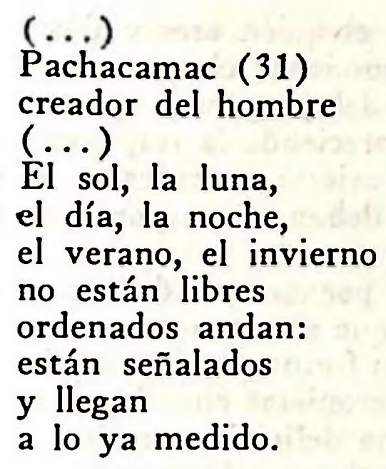

Como es posible observar en estos pasajes del poema se sintetiza su definición en forma precisa, como algo que se da ya acabado y cumplido en el tiempo y en la realidad objetiva. En contraste se dan otros versos que revelan lo indefinible, lo insituable y la imposibilidad de acercamiento real, visual, a Wiracocha, cuando se le inquiere:

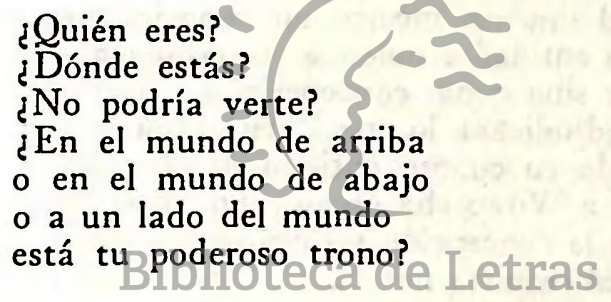

Luego han de reiterarse fas preguntas, con" una variante de exigencia de comunicación a través del lenguaje:
¿Quién eres?
¿Dónde estás?
¿Qué arguyes?
¡Habla ya!

Se da en esta estructura del poema un contraste de mayor significación que la surgida en el mito. Si en el mito la primera creación is presentada en obscuridad y la segunda en claridad, en el poema el contraste se da a través de dos formas conceptuales. La primera es claramente definitoria, cerrada a través de los atributos creativos que se le asignan, y así la vemos en el mito, pero la segunda es todo lo contrario, implica desconocimiento de la cuestión para poderla cerrar

(31) Igualmente se mantiene el vocablo Pachacamac sin traducir. que significa "Creador de la tierra", a fin de no confundir al lector en la lectura del verso siguiente que alude a la creación del hombre. 
en una definición, más aún vincula el quién eres y dónde estás a la respuesta hablada que pudiera proporcionar el ser a quien se invoca.

Queda así delineado un orden del preguntar que sí responde al qué ha podido hacer Wiracocha, apareciendo la respuesta en un crear efectivo, real o visible, pero que no acierta a contestar sobre quién es ni dónde está, cuestiones éstas que deben ser respondidas por el propio Wiracocha.

Esta ambiguedad intrínseca del poema, que delínea la concepción misma de Wiracocha como entidad que se reconoce a través de su poder, pero que no es posible definir en forma precisa, explica el por qué de las variantes encontradas en los cronistas cuando en su indagación trataron siempre de encerrarlo en una definición precisa y concreta de acuerdo con las exigencias conceptuales escolásticas.

\section{3) LAS DIFERENTES CONCEPTUALIZACIONES DE WIRACOCHA}

El objeto de esta indagación es probar que a la venida de los españoles se daba en el imperio incaico un conocimiento generalizado acerca de una máxima entidad a quien se le reconocía, no en términos cerrados de definición sino como concepción bipolar: cerrada y definida en cuanto se le adjudicaba lo creado en el universo y en el mundo, abierta e indefinida en cuanto entidad desconocida.

El mito presenta a Wiracocha en función de la creación realizada, el poema sintetiza la concepción misma en sus términos bipolares. Veremos ahora cómo el cronistatnos a a a proporcionar diferentes conceptualizaciones acerca de Wiracecha que representan en última instancia un intento de definir esta entidad.

Los cronistas que traen información sobre este problema, recepcionan términos complejos, lingüísticos o idiomáticos, que se refieren a una entidad suprema. Casi siempre la fórmula expresiva incluye en su formación el vocablo Wiracocha, o denominaciones en lengua quechua con igual significación traductiva.

Lo interesante, a nuestro modo de ver, es que cada intento de cerrar en una definición a esta entidad suprema, procura hacernos inteligible su existencia.

Lo que hemos considerado pertinente, dado que no es posible unificar los criterios interpretativos proporcionados por los cronistas, es agrupar la información recogida en cuanto expresa términos afines - características semejantes.

Sea Hacedor o creador, incomprensible dios, movedor y causa de las demás causas, el principio entendido como luz eterna, el poder y mando de todo lo existente, lo que trata de demostrar el cronista, es la presencia, en el imperio incaico, de un ser que permitía explicar coherentemente la realidad y el orden del universo y el mundo. 
Así pues conviene ahora presentar, bajo los diferentes rubros conceptuales enunciados arriba, la información recogida:

\section{1) Como Hacedor y creador.}

Este criterio está sustentado por Juan de Betanzos, Pedro Cieza de León, Francisco López de Gómara, Cristóbal de Modina, Martín de Murúa, Pedro Sarmiento de Gamboa, José de Acosta y Román Gamora.

A) Para Juan de Betanzos, Viracocha Pachayachachic era el hacedor o creador del mundo y dice así: "... ellos tienen que haya uno que es el Hacedor, a quien ellos llaman Viracocha Pachayachachic, que dice Hacedor del mundo, y ellos tienen que éste hizo el sol y todo lo que es criado en el cielo y tierra..." (32).

B) Manifiesta Pedro Cieza de León que, "Estos naturales del Collao dicen lo que todos los mas de la sierra, que el hacedor de todas las cosas se llama Ticeviracocha..." (33).

C) Para Francisco López de Gómara, Pachacama "significa criador, y desterro a Con (. .) crió él de nuevo los hombres y mujeres como son agora, y proveyóles de cuantas cosas tienen..." (34).

D) En Cristóbal de Molina se alude a "... al Hacedor, a quien en lengua de éstos le llaman Pacha yachachi, y pot otro nombre Ticsi Viracocha, que quiere decir incomprensible dios..." (35).

E) Martín de Murúa consigna, que es a “...Tipsi Viracocha, (...) a quien tenían por criador del mundo..." (36).

F) Pedro Sarmiento de Gamboa manifiesta “...Dicen los naturales desta tierra, que en elcprincipio, beantes que el mundo fuese criado, hubo uno que llamaban Viracocha. El cual crió el mundo oscuro y sin sol ni luna ni estrellas; y por esta creación le llamaron Viracocha Pachayachachi, que quiere decir Criador de todas las cosas" (37).

G) José de Acosta dice al respecto “...comúnmente sienten y confiesan un supremo señor y hacedor de todo, al cual los del Perú llamaban Viracocha, y le ponían nombre de gran excelencia, como $\mathrm{Pa}$ -

(32) Betanzos, Juan de. Obra cit. Cap. XI, p. 31.

CI, p. 444 .

(33) Cieza de León, Pedro. La Crónica del Perú. Tomo II, Cap.

(34) López de Gómara, Francisco. Historia General de las Indias. Tomo I, p. 233 .

(35) Molina, Cristóbal de. Obra cit. I, p. 15.

(36) Murúa, Martín. Historia del Origen y Genealogia Real de los Reyes Incas del Perú. Libro II, Cap. II, pp. 108-109.

(37) Sarmiento de Gamboa, Pedro.-Obra cit. (6), p. 207. 
chacamac o Pachayachachic, que es criador del cielo y la tierra, y Usapu, que es admirable, y otros semejantes..." (38).

H) Por último, nos referiremos a Román y Zamora quien menciona a “...Conditi Boracocha, que en la lengua del Cuzco quiere decir Hacedor del mundo; (...) miraba y gobernaba todas las cosas y proveía el linaje humano..." (39).

Estos criterios que en lo esencial se refieren a un creador o hacedor, curiosamente han recogido diferentes vocablos en quechua, o sea que si en la traducción al significado en español se da un criterio común, en cuanto a la denominación presentan expresiones idiomáticas diferentes. Esto en realidad no es alarmante, ya que hemos encontrado en el mito y en el poema realizaciones de Wiracocha que explican esta insistencia del cronista sobre su acción creadora, y que es natural que tuvieran expresiones lingüísticas específicas, como cuando se le llama Pachacamac, que quiere decir "hacedor de la tierra", usando camac como hacedor o Pacha yachachi, usando yachachi que también significa hacedor.

En resumen, todos estos cronistas ponen énfasis en el aspecto creativo, que justamente corresponde a una de las polaridades que en nuestra interpretación ofrece esta entidad, y que es la más clara y definida.

Sin embargo llama la atención el hecho de que se dé una fuente de información en la cual colateralmente a la adjudicación creativa, se le postula:

\section{2) Como incomprensiblelidioseca de Letras}

Para Cristóbal de Molina como ya hemos señalado “...el Hacedor, a quien en lengua de éstos le llaman Pacha yachachi, y por otro nombre Ticsi Viracocha, quiere decir incomprensible dios..." (40).

Esta doble traducción de Molina de Hacedor, al mismo tiempo que incomprensible dios, confirma en la crónica la doble vertiente que opera en la esencia explicativa de esta entidad, sin proporcionar aclaraciones sobre la doble significación que presenta. Esta referencia respalda nuestra tesis interpretativa en el sentido de que Wiracocha como concepto definitorio es bipolar, una faceta conocida y otra desconocida, incomprensible, que la cautelosidad del pensar indígena no encierra en una definición.

Nos ocuparemos ahora de los cronistas que se refieren, bajo distintas conceptualizaciones, a esta entidad: como movedor y causa, y como principio.

(38) Acosta, José de. Obra cit. Libro V, Cap. III, p. 141.

(39) Román y Zamora. República de Indias. Tomo XIV, Vol. I, Cap. I, pp. 65-66.

(40) Molina, Cristóbal d.e. Obra cit. I, p. 16. 


\section{3) Movedor y causa de las demás causas.}

Miguel Cabello Valboa manifiesta que “...Viracocha entre los antiguos Yngas fue (y a sido) nombre de grandíssima excelencia en tanto grado que quando se cayó en la cuenta de que auia en el Cielo un universal y todopoderoso movedor, y causa de las demas causas $(\ldots)$, por excelencia y grandeza y por no hallar nombre que significasse mas magestad le llamaron Ticciviracocha" (41).

\section{4) El Principio.}

Según Blas de Valera: "Creyeron y dijeron que el mundo, cielo y tierra, y sol y luna fueron criados por otro mayor que ellos: a este llamaron Illa Tecce (el principio), que quiere decir Luz eterna. Los modernos añadieron otro nombre, ques Viracocha..." (42).

5) Como poder y mando de todo lo existente.

A) Lo traduce Polo de Ondegardo, llamándolo en lengua quechua Ticci Viracocha, y aclarando que ".... a él le atribuyen principalmente el poder y mando de todo, y a las otras Huacas, como a los señores, o Dioses particulares cada uno en su casa y que eran intercesores para con el Ticci Viracocha" (43).

B) José de Acosta, en otro pasaje, desbordando su concepción de Hacedor que hemos presentado antes, manifiesta que a Ticciviracocha se le "....atribuían principalmente el poder y mando de todo, y a los otros como diosses os oseñores particulares çada uno en su casa, y que eran intercesores para con el gran Ticciviracocha" (44), “...estando todo debajo de sư poder..." (4) y agregando que "...nningún otro Dios hay (...) sino uno; y que todo lo demás no tiene propio poder, ni propio ser, ni propia operación..." (46).

Aparece así en las últimas concepciones anotadas una significación filosófica más compleja y unitaria y por esta razón hemos reservado el juicio que emite el Padre Bernabé Cobo, quién en última instancia sería el que habría calado con más sentido y profundidad en la existencia y el significado de Wiracocha, cuando no sólo confirma

297.

(41) Cabello Valboa, Miguel. Miscelánea Antártica. Cap. XIV, p.

(42) Anónima. Relaciones de las Costumbres Antiguas de los Naturales del Perú p. 135.

(43) Polo de Ondegardo, Juan. Informaciones acerca de la Religión y Gobierno de los Incas. Tomo III, p. 6.

(44) Acosta, José de. Obra cit. Libro V, Cap. IV, p. 144.

(45) Idem. Libro VI, Cap. XXI, p. 200.

(46) Idem. Libro V, Cap. III. p. 142. 
que a Viracocha se le atribuye "...el poder y mando de todo... (47), sino que lo interpreta como ".. la primera causa..." (48), a quien daban "títulos y nombres de gran excelencia: los más honrosos y usados eran dos, ambos translaticios y de grande énfasis: Viracocha el uno, y el otro, Pachayacháchic; al primero solían anteponer o posponer algunas palabras, diciendo unas veces Ticciviracocha, y otras Viracochayacháchic. El de Ticciviracocha era tenido por misterioso, el cual interpretado, significa 'fundamento divino'; el nombre de $\mathrm{Pa}$ chayacháchic" quiere decir "Criador del mundo"; y la misma significación tiene el de Viracochayacháchic" (49).

Con esta última cita, la más importante por supuesto, creemos haber recorrido un camino que nos permite ahora delinear el verdadero sentido y significación que adjudicamos a lo que hemos venido llamando "entidad".

En primer lugar no podemos negar su existencia, que ha quedado probada a través de las reiteradas menciones de los cronistas y a lo largo de toda la exposición precedente. El que siempre se le haya considerado como entidad religiosa obedece fundamentalmente al hecho de que el cronista, al reconocerlo como la máxima entidad que explicaba todo lo existente, realizó una transposición interpretativa inconsciente en términos de filosofía escolástica. Esto explica también la insistencia del cronista por encerrarlo en una definición, que casi siempre efectuó a partir de una traducción de vocablos quechuas, cargada, igualmente, de sentido interpretativo escolástico.

La cautelosidad del pensar indígena no encierra a Wiracocha en una definición. Examinado como concepto definitorio, aparece con una naturaleza bipolar, una faceta conocida y definida que resume todo lo creado como "existente uactual"li (pasado-presente), y otra desconocida e incomprensible que apunta hacia todos sus poderes y posibilidades de realización (futuro). Por eso su actuar en el pasado se ofrece imperfecto o defectuoso, y es sólo en cuanto que rectifica y perfecciona su creación, es decir su obra, que adquiere la nota esencial más importante que es la de Poder y mando de todo lo existente, constituyéndose en explicación ontológica.

Este poder y mando atribuido a Wiracocha, por ser una cualidad abstracta, revela no sólo lo indefinible, lo insituable, la imposibilidad de acercamiento real, sino lo desconocido; es en última instancia el reconocimiento, a través de la reflexión, de un poder que trascendiendo la experiencia adquiere categoría de entidad ontológica.

(47) Cobo, Bernabé. Obra cit. Libro XII, Cap. IV, p. 155.

(48) Loc. cit.

(49) Cobo, Bernabé. Obra cit. Libro XIII, Cap. IV, p. 155. 


\section{BIBLIOGRAFIA}

ACOSTA, José de. Historia Natural y Moral de las Indias. En Biblioteca de autores españoles (No. 73). Obras del padre José de Accsta. Madrid, Ed. Atlas, 1954. pp. 1-247.

ANONIMA. Relaciones de las Costumbres Antiguas de los Naturales del Perú. En Tres Relaciones de Antigüedades Peruanas. Buenos Aires, Ed. Guaranía, 1959. pp. 135-281.

ANONIMO. Ollantay, Cantos y Narraciones Quechuas. Versiones de J. M. Arguedas, César Miró y S. Salazar Bondy. Lima, Patronato del libro peruano, 1957. pp. 59-62.

BETANZOS, Juan de. Suma y Narración de los Incas. En Biblioteca de autores españoles (No. 209). Crónicas Peruanas de Interés Indígena. Madrid, Ed. Atlas, 1968, pp. 1-55.

CABELlo VAlBoA, Miguel. Miscelánea Antártica. Lima, Universidad Nacional Mayor de San Marcos, Instituto de Etnologia, 1951.

CIEZA DE LEON, Pedro. El Señorio de los Incas. Lima, Instituto de estudios peruanos, 1967.

CIEZA DE LEON, Pedro. La Crónica del Perú. En Biblioteca de autores españoles (No. 26). Historiadores Primitivos de Indias. Madrid, Ed. Atlas, 1947. Tomo II, pp. 349-458.

COBO, Bernabé. Historia del Nuevo Mundo. En Biblioteca de autores españoles (No. 92). Obras del padre Bernabé Cobo. Madrid, Ed. Atlas, 1964. Tomo II, pp. 7-275.

LOPEZ DE GOMARA; Francisco. Historia General de las Indias. En Biblioteca de autores españoles (No. 22). Historiadores Primitivos de IndiasolMadrid, Ed. Atlas, 19460 "Tomo I, pp. 155-455.

MOLINA, Cristóbal de. Ritos y Fábulas de los Incas. Lima, Ed. Futuro, 1959.

MURUA, Martín. Historia del Origen y Genealogia Real de los Reyes Ingas del Perú. Madrid, Consejo Superior de Investigaciones Científicas, Instituto Santo Toribio de Mogrovejo, 1946.

ONDEGARDO, Polo de. Informaciones acerca de la Religión y Gobierno de los Incas. Notas biográficas y concordancias de los textos por Horacio H. Urteaga. Lima. Imprenta San Marti, 1916-1917. Tomos III y IV.

ROMAN Y ZAMORA. República de Indias, Idolatria y Gobierno en México y Perú. Madrid, Colección de libros raros, 1897. Tomo XIV, volumen $I$.

SANTA CRUZ PACHACUTI YAMQUI, Joan de. Relaciones de Antigüiedades deste Reyno del Perú. En Biblioteca de autores españoles (No. 209). Crónicas Peruanas de Interés Indigena. Madrid, Ed. Atlas, 1968. pp. 279-311. 
SARMIENTO DE GAMBOA, Pedro. Historia Indica. En Biblioteca de autores españoles (No. 135). Obras del Inca Garcilaso de la Vega. Madrid, Ed. Atlas, 1965. Apéndice, Tomo IV, pp. 189-279.

VALCARCEL, Luis E. Etnohistoria del Perú Antiguo. Lima, Universidad Nacional Mayor de San Marcos, Patronato del libro universitario, 1959.

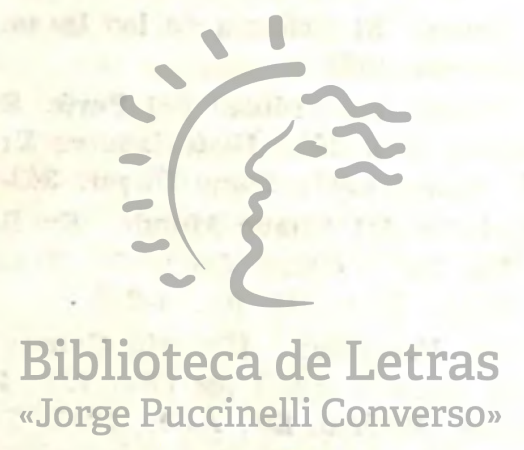

